\title{
Impact of Second Wave Covid -19 on Daily Wage Earners
}

\author{
Mrs. Archana Saikia1, Miss Angkita Borpatra Gohain² \\ ${ }^{1}$ Assistant Professor, Dept. of Management CKB College, Jorhat \\ ${ }^{2}$ Assistant Professor, Dept. of Commerce Don Bosco College, Jorhat
}

\begin{abstract}
The impact of Second Wave COVID-19 Pandemic on the lives of Daily Wage Earners has been largely devasted at unprecedented levels during the Lockdown and it has driven our economy to recession. India's COVID-19 cases have once again penetrated to increase in numbers with every passing day. With the rise in number of COVID-19 cases, at the same time increase the rate of death especially the people who are affected by COVID-19. As Government imposing Curfews, once again the Daily Wage Earners are facing uncertainty. Daily Wage Earners include construction workers, street vendors, painters, weightlifting, masons, Rickshaw-puller and many more. This informal sector workers does not have necessary resources for survival. Wages play an important role in maintaining the livelihood as they rely on their Daily Wages. This results in decrease of purchasing power due to job losses or pay cuts. The level of anxiety and fear has increased among the lives of Daily Wage Earners. The pandemic has worsened the condition of Daily Wage Earners as it has put the risk of facing extreme poverty. The workers fighting on two fronts of life: Firstly, to protect themselves from pandemic threat and Secondly to battle for survival. This study will elucidate the difficulties outbrave by the Daily Wage Earners. A survey was taken among 150 Daily Wage Earners to derive the problems come across by them. The research work is based on primary source of data collected by direct questionnaire to the Daily Wage Earners of Jorhat District of Assam.
\end{abstract}

KEYWORDS: COVID-19, Daily Wage Earners, Lockdown, Government, Curfew, Livelihood.

\section{INTRODUCTION}

The Second Wave COVID-19 Pandemic has promptly escalation across the World. The Assam Government imposes restriction due to exponential rise in cases. On $5^{\text {th }}$ may, 2021 Government issue shut down of shops at $2 \mathrm{pm}$ and curfew has been extended from $6 \mathrm{pm}$ to $5 \mathrm{am}$. Then again on $16^{\text {th }}$ may, Government issued an order for total ban on movement of individuals from 12noon to 5am daily. The streets of Assam remains largely empty due to Government's Lockdown or Curfew. The days of Curfew drastically affected the lives of Daily Wage Earners in Assam. A Daily Wage Worker earn Rs.400 to Rs.500 a day but now it is difficult to get work. Many Workers are already excluded from work by the owner. Workers are forthwith turned out to be unemployed. Particularly, workers are facing variety of problems such as Wages have dipped by half, Job Loss, Food prices increased, Hunger, no other source of income. The lives of Daily Wage Earners got pathetic everyday. This is time when government employees, NGO's to donate a grocery kit and save them from deprivation and other health issues.

\section{LITERATURE REVIEW}

*Sakshi Sahni, Aulakh Singh Rawal (Nov 2020), in the paper examine the impact of COVID-19 on Rural Migrants in India. It focused mainly on Social Impact and Economic Impacts faced by Rural Migrants. From the study it is observed that 42 crore people have received Financial Assistance, free food grains supply and Rs.500 deposit to Jandhan amounts of women. But after losing many lives of Migrants. Migrants play an important role in our economy without which the economy will not be to continue.

*Padmakar Shahare, Mukul Burghate (Feb 2021), the Impact and Challenges of COVID-19 Lockdown on Daily Wage Workers and their livelihood mentioned in their paper that reveals the standard of living for Daily Wagers during the Blockade period. Paper takes both questionnaires and hypothesis for the study. The study revealed the majority of Workers are illiterate and face unitedly financial and food problems. Daily Wage Workers endure a lot to live a routine life.

*Dr.kishoreKumar Das, Shalini Patnaik (May 2020), clarify in their research titled " The Impact of COVID-19 in Indian Economy -An Empirical Study". The paper mainly focused on adverse impact on Indian Economy. The Impact of COVID-19 pandemic lead to slowdown in domestic demand. Economy GDP drained to its lowest level more than six years during the fourth quarter of 2019-20. Indian's growth for next year 2020-21 is outlook in between $5.3 \%$ to $5.7 \%$.

*Monika chaudhary, P.R.Sodani, Shankar Das, "Effect of COVID-19 on Economy in India: Some Reflections for policy and programme". The paper mainly focuses on 
analysing the impact on affected sectors such as aviation, tourism, retail, capital markets, MSMEs and oil. And recommend some programe and policy measures to overwhelm the situation of COVID-19. India must consider again on her development pattern and make it more comprehensive.

\section{OBJECTIVE OF THE STUDY}

1. To analyses the Impact of Second Wave COVID-19 on Daily Wage Earners.

2. To find out the difficulties faced by the Daily Wage Earners.

\section{RESEARCH METHODOLOGY}

The Research Work spotlight on the Daily Wage Earners. The nature of the study was all the class of Daily Wage Earners in Jorhat District, Assam. In order to bring about the detached of the study, data was collected primarily through set of questionnaires directly from the respondent. The respondent enclosed all the categories of Daily Wage Earners includeStreet Vendors, Painters, Plumbers, Rickshaw-puller, Auto Driver, Mason, Construction Workers, Weightlifting (Market place) and remains. The feedback acquired were evaluate pleasantly by using statistical tools.

\section{ANALYSIS AND INTERPRETATION}

Figure 1: Age of the Respondents

\section{Age of Respondents}

$$
\text { - Upto } 30 \text { - 31-40 - 41-50 - Above } 50
$$

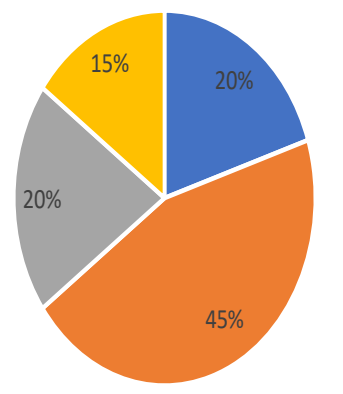

Interpretation: Out of 150 respondents, it is seen that many of the respondents i.e. $45 \%$ of Workers are in between 31 to 40 years of age, whereas only $15 \%$ responses are from above 50 ages, $20 \%$ from up to 30 and rest $20 \%$ from 41 to 50 years of age.
Figure 2: Educational Qualification Educational Qualification

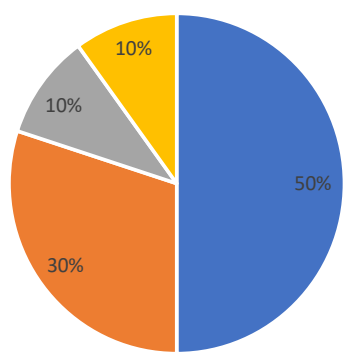

- Illiterate

- Schooling

- Diploma

- Degree

Interpretation: From the survey, it is found that $50 \%$ of the respondents are illiterate, $30 \%$ of the respondents have only completed school and rest have completed their diploma and degree in the same portion.

Figure 3: Cause for Doing Daily wage work

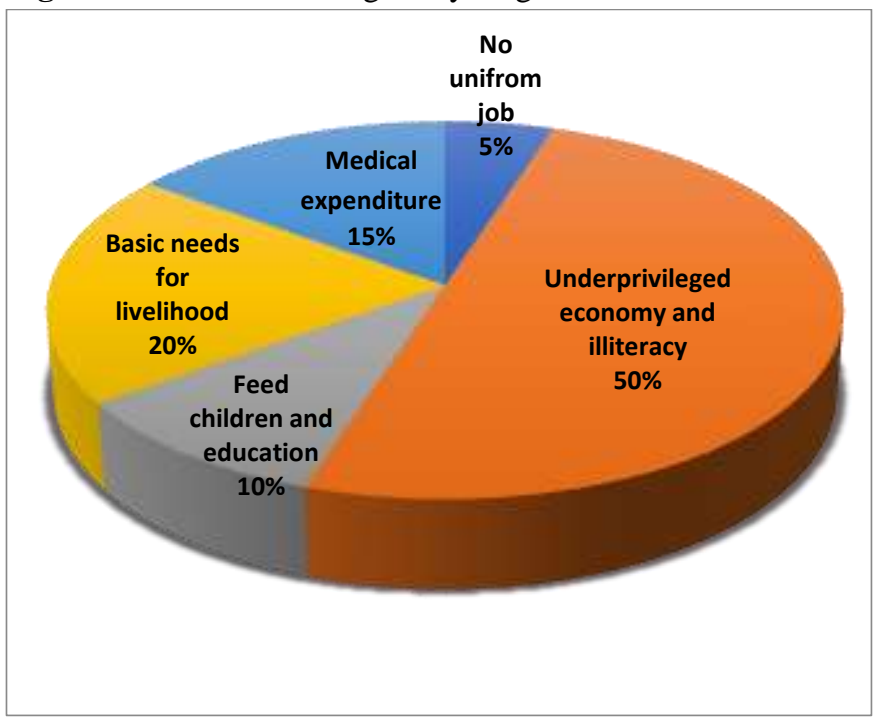

Interpretation: It is seen that $50 \%$ of Workers doing daily wage work due to underprivileged economy and illiteracy, so they have to cover basic needs for survival, medical overheads, to feed children's and their education.

Figure 4: Source of Income

\section{Source of Income}

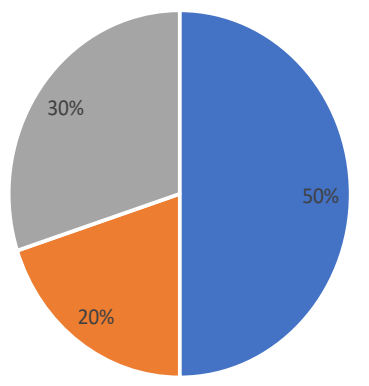


Interpretation: From the study, it is concluded that $50 \%$ of the respondents used government assistance for their livelihood. $20 \%$ of the respondents borrowed money from neighbours and many workers women were force to borrow from various micro finance group and self help group to make their needs for livelihood. And remaining 30\% approached both.

Figure 5: Nature of Difficulties Faced

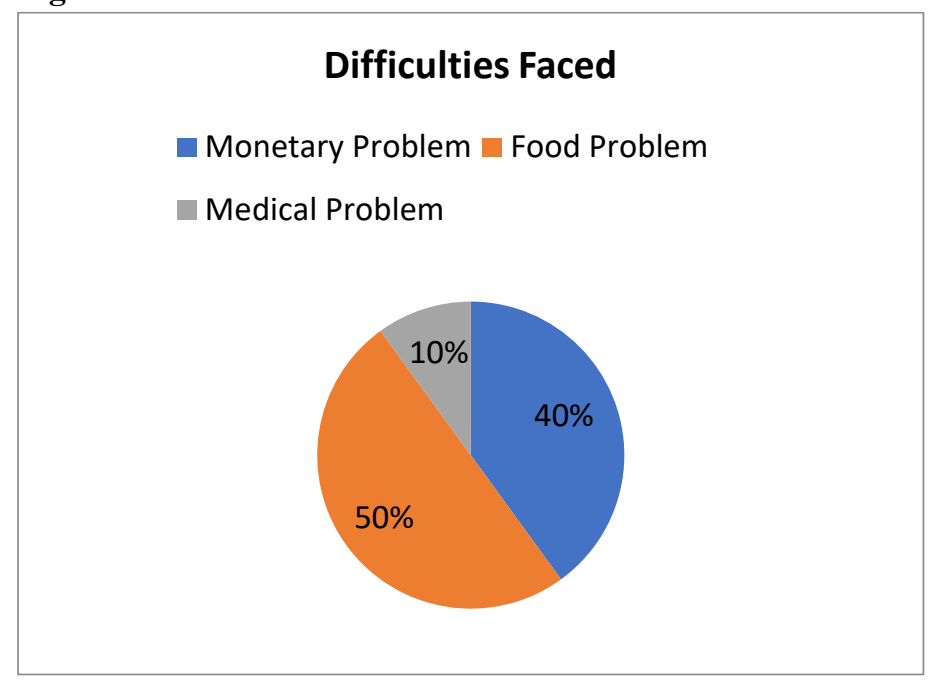

Interpretation: The figure represents, the nature of difficulties faced by daily wage earners. It shows that $40 \%$ of respondents face monetary problem and 50\% face food problem or grocery problem. $90 \%$ of workers simultaneously face food and money problem as they are the basic necessities of life. And $10 \%$ face medical problem.

Figure 6: Mental Health of the Respondent

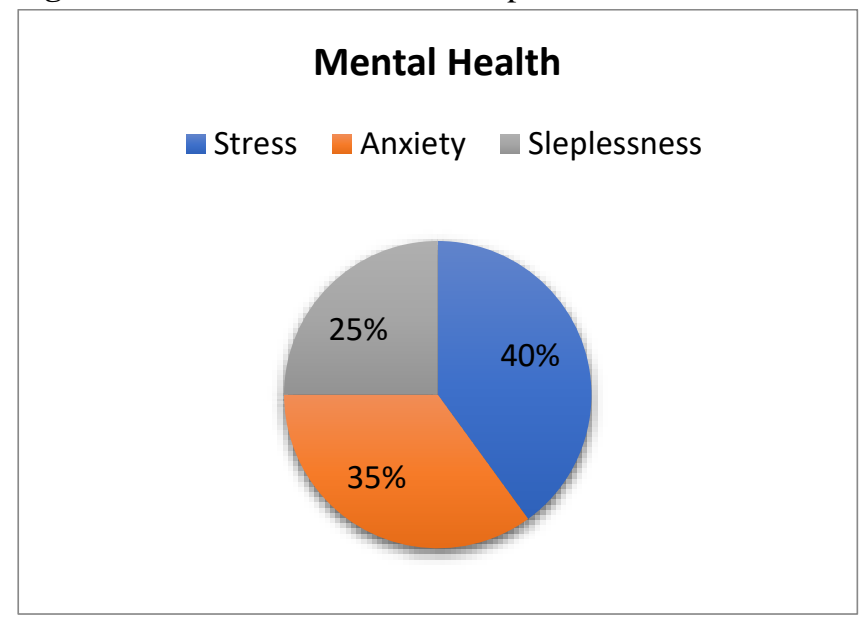

Interpretation: It describes the mental health of the respondent during blockade period, who had lost their livelihood. Due to financial uncertainty about $40 \%$ of the respondents suffers from stress, as stress increase domestic violence against women and children. $35 \%$ of the respondent had anxiety and other $25 \%$ had problem relating to sleeplessness.
Figure 7: Did you receive wage during Second Wave COVID-19 Curfew?

\begin{tabular}{|l|l|}
\hline & Yes $\square$ No \\
$75 \%$ & \\
\hline & \\
\hline
\end{tabular}

Interpretation: As Government imposes total ban on movement of individual from 12noon to 5am, doing work for 3 to 4 hours no employer/owner provide full wages. Only $25 \%$ of the respondents received half wages. And remaining $75 \%$ of respondents no longer received wages.

Figure 8: Did your Owner or employer provide you Grocery kit during the period?

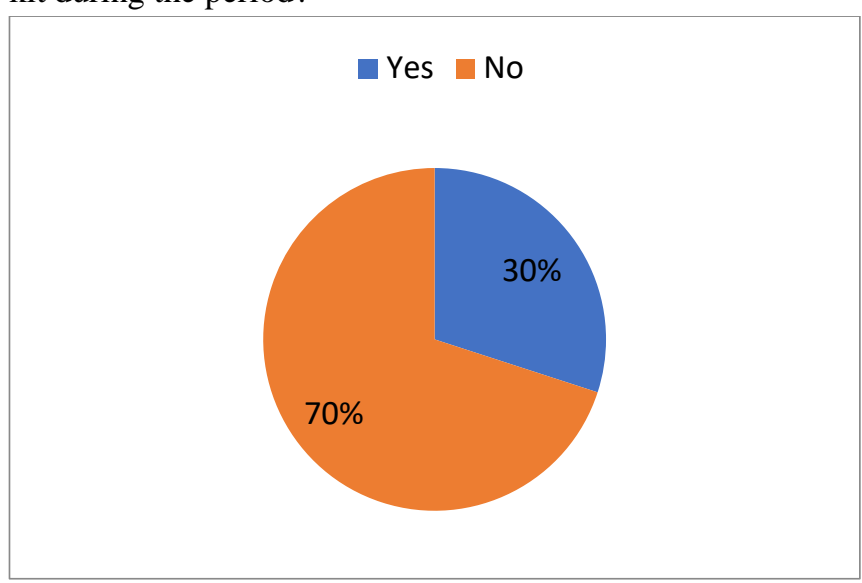

Interpretation: It is seen that, only $30 \%$ of the respondent were received grocery kit from their owner or employer. And rest $70 \%$ of the respondents were not received any grocery kit.

Figure 9: Did you get support from the Government?

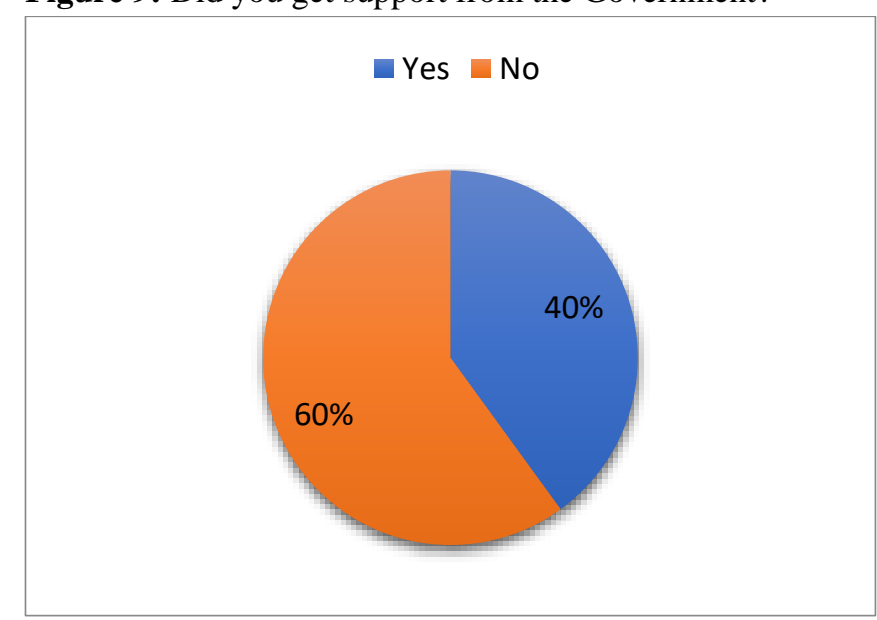


Interpretation: From the survey, it is clear that $40 \%$ of the respondents got help from the Government and remaining $60 \%$ of the respondents did not get any support due to unaware of Government assistance.

\section{FINDINGS}

1. Majority of respondents are of 31 to 40 years of age doing daily wage work and $50 \%$ of workers are illiterate and live underprivileged economy condition, so they have to envelope the basic needs for survival, medical overhead and children's education.

2. The main sources of livelihood for daily wage earner were generally dependent on government schemes, borrowings from relatives and various micro finance groups. And few workers had to approach both to make ends meet for their family.

3. The most rated difficulties faced by workers are food and money problem as they are the basic necessities of life for survival.

4. Due to financial uncertainty, workers suffer from emotion stress, depression, anxiety.

5. It is also found that due to curfew only few workers got half the usual wages.

6. Some employer/owner provides grocery kit to their workers for livelihood support.

7. From the analysis it is found that due to lake of awareness about government assistance $60 \%$ of workers did not seek help from government.

\section{CONCLUSION}

The second wave COVID-19 extremely drives challenges to the economic informal sector. Due to curfew, daily wage earners faced a heavy loss. They depend on daily wage for their livelihood, but due to financial uncertainty they have to face monetary as well food crisis. It is the foremost responsibility of the government to safeguard the livelihood conditions and economy of the daily wage earners. And the Assam government has to made complete arrangement for the daily wage workers before the implementation of curfew. There is need for general information campaigns about government assistance provided for poor people of Assam. The security and mental health of workers are most important for growth of the economy. It is necessary to offer reliability to daily wage workers to retain them economically pleasant. Thus, the problems faced by daily wage earners during blockade period have been analyzed.

\section{REFERENCES}

1. Das, Dr.kishore kumar and patnaik shalini (2020), "The Impact of COVID-19 in Indian Economy- An Empirical study", International journal of Electrical Enginerring and Technology (IJEET), volume 11, Issue 3, May 2020.
2. Bhuyan Bhaskar, Borah Bitu, Gogoi Rupam (2020), "Impact of COVID-19 in the society and culture of Assam and its Future," European Journal of Molecular \& clinical medicine ISSN 2515-8260, volume 07, Issue 09, 2020.

3. Gogoi Himanshu, "A Review on Lockdown due to COVID-19 and its impact on rural economy based on small Tea Gardens in Tingkhong, District, Assam," International Journal of Creative Research Thoughts (IJCRT), volume 8, Issue 6 June 2020.

4. P.Titus Lalith Antony, Rani Leslie, M.P. Brundha, Priya Jathi (2020), "Problems faced by daily labourers during COVID-19 lockdown- A questionnaire survey," International Journal of current research and review, vol 12- Issue 19.October 2020.

5. Shahare Padmakar, Burghate Mukul, Sheikh Niyaj, "The impact and challenges of COVID-19 lockdown on Daily wage workers and their livelihood," ISSN: 2249-6661, vol-44 No.-01(vi):2021.

6. Chaudhary Monika, Sodani P.R, Das Shankar, "Effect of COVID-19 on economy in India: Some reflections for policy and programme", Journal of Heath Mangement, 22(2) 169-180, 2020.

7. Sahni Sakshi, Aulakh Rawal (Nov.2020), "Impact of COVID-19 on rural migrants in India" Researchgate, kalpaz publications (pp.29-30). 